\title{
Quality Management Model in Banana Production: Case Study in Mala-Perú
}

\author{
Manuel Diaz-Umpire1, Luis Chariarse-Vargas ${ }^{1}$, Fernando Sotelo, $\mathrm{MSc}^{1}$ and Edgar Ramos, $\mathrm{Mg}^{1}$ \\ ${ }^{1}$ Ingeniería Industrial, Universidad Peruana de Ciencias Aplicadas, Perú, \\ $\{\mathrm{u} 201316992, \mathrm{u} 201410922$, pcinjsot, pcineram $\} @$ upc.edu.pe
}

\begin{abstract}
This document proposes a Quality Management model based on the characterization of processes and good agricultural practices established by Ecuador, which will have four subprocesses that will be responsible for standardization and will cover all aspects necessary to achieve increased productivity : quality planning, quality control, internal quality audit and quality training, so that with these tools the farmer achieved an increase in production and also of the income generated from the implementation of the quality system proposed in the present document.
\end{abstract}

Keywords- Agriculture, Quality Management, Process characterization, Banana, Processes.

\section{INTRODUCTION}

It is known that Peru is recognized worldwide for its great biodiversity, for its agricultural and livestock tradition. It would be extensive to list the benefits and benefits that agrarian Peru has offered and has offered to humanity, since ancient times. Those who have had, and have, contact with agriculture and livestock recognize the great potential that Peru manages in the agricultural and forestry sector.

Therefore, in this document, one will work with a particular fruit, the banana, because it is within the group of fruits and nuts in Peru, which has the second best market price compared to other groups of products such as cereals and tubers and, also, it is worth mentioning that within this group the banana is the one with the highest production. Banana is a fruit of Asian origin, whose consumption has spread throughout the world, is grown in all tropical regions throughout the year and is of fundamental importance to the economies of many developing countries. In terms of gross value of production, bananas are the fourth most important food crop in the world, after rice, wheat and corn.

However, despite the fact that the banana produced in Peru is exported or destined for internal consumption, there are a large part of farmers who are limited in their efforts to obtain a quality product suitable for export and internal consumption, since they do not work under a quality system that allows them to optimize their process so that farmers can guide information about their crops, machinery and work so that customers are satisfied with the products they buy.

The quality management system, therefore, aims at coordinating procedures and resources to improve the quality of the offer. A satisfied customer always implies a benefit for the company: higher profits and loyalty.

Digital Object Identifier (DOI):

http://dx.doi.org/10.18687/LACCEI2020.1.1.314

ISBN: 978-958-52071-4-1 ISSN: 2414-6390

\section{LITERATURE REVIEW}

Faced with the great growth opportunities that small and medium enterprises have, [1] points out that innovation is an important way for companies to increase their competitiveness. An analysis of the literature on innovation shows that almost all studies in that field focus on large companies. Therefore, [1] points out that it is necessary to make innovations in micro, small and medium enterprises in order to increase their productivity. Therefore, a Quality process based on Quality Management for banana farmers is proposed.

Certified Agriculture (CA) is a Quality Management System (QMS) that aims to testify the benefits of implementing a productive model based on Direct Sowing and the principles of sustainable, profitable and high productivity agriculture. Farmers have a great responsibility in the application of productive schemes that support these precepts, especially in today's globalized world, where society increasingly demands respect for the environment and for people.

This QMS aims to provide tools to achieve professional, efficient and sustainable agronomic and business management, through knowledge and information analysis, including this: records of the activities carried out, quality indicators of the natural and human resources involved, and indicators of energy and productive efficiency.

In addition, certified agriculture offers the possibility for society to know how food production processes are carried out and what is their impact on the environment, allowing to capture the value of the positive externality it exerts on it.

In summary, Certified Agriculture as a quality management system implies improving efficiency and effectiveness, and consequently, the profitability of the agricultural enterprise, the forecast of all types of contingencies and the possible opening of new markets or other business opportunities. For the company that implements it, it means identifying internal strengths and weaknesses, improving processes and reducing hidden costs in the post of continuous improvement. On the other hand, it allows loyalty of suppliers and customers, as well as achieving the recognition and external positioning granted by the social audit.

Additionally, [2] indicates that since its inception the field of quality management has been characterized by a practicedriven development. Although quality management has reached maturity as a research field based on empirical research, its professionals still struggle to adapt the implementations to reap their benefits. In addition, [2] identifies three issues related to the future challenges of quality management: the adaptability of organizations to rapid changes 
in the business environment, quality as a strategic concern for business owners and ownership of business management. the quality. When analyzing these, six proposals were proposed for future research to reduce the possible relevance gaps. Future research should focus on how to make quality management a strategic concern for homeowners, and explore how it can contribute to the ambiguity of the organization and adaptability. Research should also determine how the context influences the way in which quality management is applied and investigate how it can improve innovation and organizational learning.

Finally, according to [3], tactical planning corresponds to the structural level in quality management, which is defined as the planning of the processes necessary to achieve the quality objectives in the organization. In addition, Betancourt affirms that with the characterization of processes, quality management is managed at a tactical level, as well as helping to describe how a process works and to comply with the requirements of the proposed standard.

Ref. [4] analyze the behavior of customers in Italy with regard to products labeled as organic and fruits with minimum production processes. The results show evidence that the attitude and willingness to pay of consumers are directly related to the characteristics of extrinsic quality, that is, external characteristics of the product as packaging, brand, certification, which is achieved through standardization and uniformity of products.

Ref. [5] the proper management of the standardization of agricultural practices is critical to the performance and quality of the fruit. They concluded, the development of its products; after three consecutive seasons, from changes shown in nutrient status, physical integrity of the plant and reducing the number of imperfects in the plant. The standardized process was handled according to the code of good agricultural practices of organic production.

Ref. [6] reinforce the idea stating that establish production standards primarily influence the quality of the same products. This relationship is positive, because in the case study of the European Union on lighters where only lighters which meet the standard of being unsuitable for children are marketed shows that the rules of the product better, and as a result, The product quality.

Ref. [7], seeking to confirm whether standardization is a key part of the microeconomic infrastructure with the benefits of reduced costs and increased quality. In this way, they pose intended to raise awareness about the importance of standardization activities, its economic effects and other, as well as the importance of participating in the standards development process within national standards bodies. The most important results of this research say that organizations benefit from the knowledge gained working on the development and adoption of standards in terms of improving their products and processes, this also has a positive relationship with the reputation of those products from the users, that is, they are recognized by customers for having constant levels of quality.
Ref. [8] investigated about exporting skills apple exporters. On the study identified that companies develop standardized processes correctly perform with higher performance in terms of quantity of exported products. Companies with skills such as communication, knowledge of rules and regulations, organization and management in exports has a significant relationship with the quantity of exported products.

Ref. [9] indicate that the heterogeneous quality fruit explains the low levels pineapple fruit export in Benin to the international market. Therefore, the authors prove that the standardization of processes and products for quality are key factors for achieving the objective of exporting.

Ref. [8] the proper management of harvest and postharvest handling of fresh produce and vegetable has a significant and positive impact on quality so that they maintain the optimum condition to reach the final consumer.

Respecting Good Agricultural Practices implies producing under a set of principles, standards and technical recommendations aimed at taking care of human health, protecting the environment and improving the conditions of workers and their families. The producer must take all necessary actions to ensure the correct and efficient use of agrochemicals, in order to minimize any negative impact on the environment and human health. To do this, you must first verify that all safety measures are complied with in regards to transport and storage of agrochemicals. In addition, you must keep an Agrochemical Stock Record, indicating quantities of product purchased and dates.

Ref. [10], in times where value creation is an important pillar for the competitiveness and sustainability of a business, BPM is a practice that should be applied to and forever. Currently, small businesses do not implement the BPM, this is because they have limited resources, lack of a global mindset and lack of strategic clarity.

The tools to perform a process characterization are: the process map, flowcharts BPMN and SIPOC:

\section{A. Process map}

The most used tool in process management is the process map, which distributes processes in three categories. According to the publication "Management by processes" of the Ministry of Development of Spain in 2005, the processes are classified as strategic, key and support. The first group provides guidelines for the company, within those guidelines are the objectives, mission and vision of the company. The second group is the operational part and is responsible for obtaining products according to customer requirements. Finally, the third group provides materials, which become the resources so that the key processes obtain excellent results and the objectives provided by the strategic ones are achieved.

\section{B. Flowchart BPMN}

The BPM is used in the industry as a support for reengineering or for the presentation of the general concept of the company's value chain so that its automation is easier. The methodologies are diverse and one of them is the BPMN, 
which is a specific language designed for the modeling of processes of various companies. It is this type of language that allows the modeling of "end-to-end" processes as it provides graphic notation so that the entire chain of operations of the company can be understood by a simple type of diagram

\section{C. $S I P O C$}

Ref. [11] SIPOC is a diagram used to categorize how several entities interact with each process, dividing it into convenient segments. The parties involved in the diagramming of the SIPOC are the following:

1) Suppliers are the people who contribute various resources to the process.

2) The resources (inputs) is all that is necessary to carry out the process.

3) Processes are the transformation activities in which value is added to the resource you have entered.

4) Outputs are the results of the processes.

5) Customers are the individuals who receive the result or exit of the process.

For the elaboration of the SIPOC, in relation to the parts described above, the steps to follow would be the following: it begins with the identification of the processes, then the inputs or inputs are identified to subsequently identify the suppliers of said inputs. Finally, we proceed to determine the exits and customers of each of the exits obtained. In addition, it is important to prepare the procedures, formats, instructions, plans, guides and records of each proposed process or subprocess

\section{MethodOLOGY}

The proposal of the Quality Management process that will be presented below will have the quality standards that must be met by banana farmers to offer a quality banana in the market and avoid the loss of banana trees during production. standards established by MAGAP (Ministry of Agriculture, Livestock, Aquaculture and Fisheries of Ecuador), taking into account that the farmer and entrepreneur will aim to increase their productivity and income, just as Ecuadorians did in 2010, which occurred after the creation of the Ecuadorian Agency for Quality Assurance - AGROCALIDAD in order to standardize and control the processes and products related to agricultural activities. In this way, the production of bananas will be oriented to comply with the proposed quality guidelines, that is to say that during each stage of the production process in which activities that affect the obtaining of quality bananas are involved, they are standardized according to the model of quality that is proposed later. This proposal of the Quality Management process will be based on the PDCA Methodology, which will be implemented in the proposed subprocesses and will be shown, specifically, in the Quality Planning subprocess. In addition, the proposed subprocesses will help banana farmers to have records of the various quality controls that are applied in the production chain. Finally, compliance with these subprocesses will be measured through internal audits and training.
The classification of subprocesses in strategic, operational and support is shown in the quality subprocess scheme in Figure 1. It is important to mention that these threads are important to successfully carry out the implementation of the proposed Quality Management

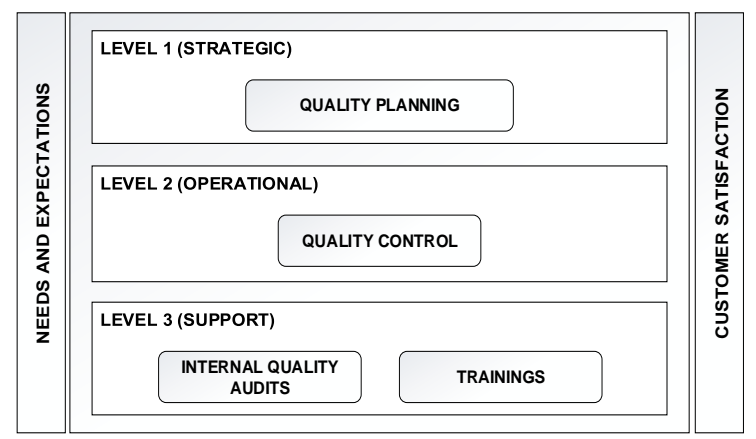

Fig. 1. Scheme of quality management subprocesses.

The proposed subprocess are divided into:

\section{A. Strategic level: quality planning}

This subprocess is related to the strategy that banana farmers must follow to increase their productivity, because it will identify the quality standards for bananas, assess the current performance of these standards and consider processes according to these standards to meet the requirements of the market. Likewise, this subprocess contributes to the vision of the microentrepreneur farmer, because it seeks to keep these standards updated according to the international certifications that exist in the market.

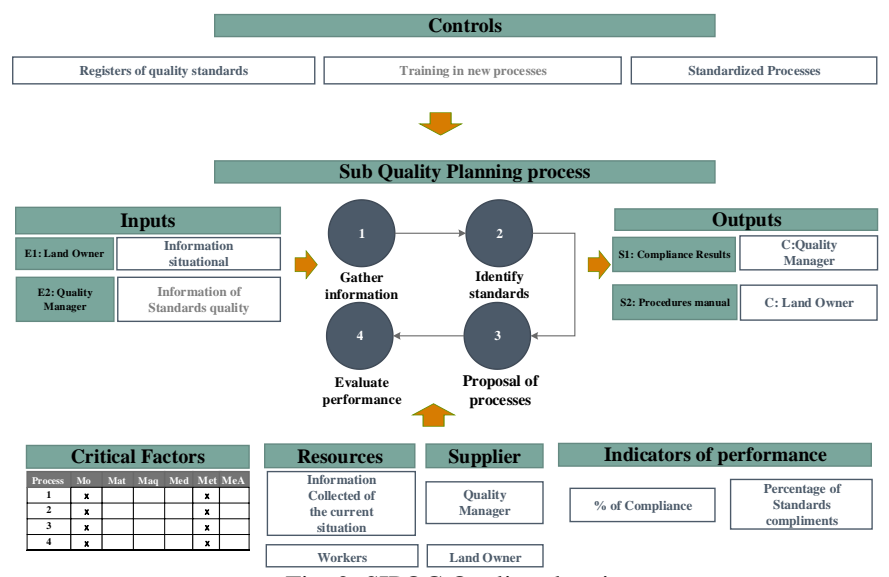

Fig. 2. SIPOC Quality planning.

As stated in the SIPOC diagram shown in Figure 2, the input for the subprocess is the situational information of the banana farmers and the quality standards information. The outputs of the process are the results of the current compliance, the procedures manual and the compliance report. The process has been established in five stages: information gathering, identification of standards, performance evaluation, process planning and updating of standards. In addition, critical factors have been identified for each; In the case of the first stage, 
labor and method are its critical factors. In this regard, the verification controls of compliance with the quality planning process have been established. The resources used are the information collected from the current situation and the personnel that will be present in the process.

The following indicator is presented for the Quality Planning subprocess:

1) Index of standards met: This indicator contributes to increased productivity, as banana farmers may have standardized production processes, which will allow farmers to negotiate at a competitive price, as it gives added value to their final product.

\section{B. Operational level: quality control}

This subprocess is related to the quality controls in the productive processes of sowing, pruning and care and harvest that the banana farmers must follow to increase their productivity, which will be managed according to the standards previously identified in the quality planning. Also, this subprocess adds value in the farmers' crop processes, and thus in the value of the final product.

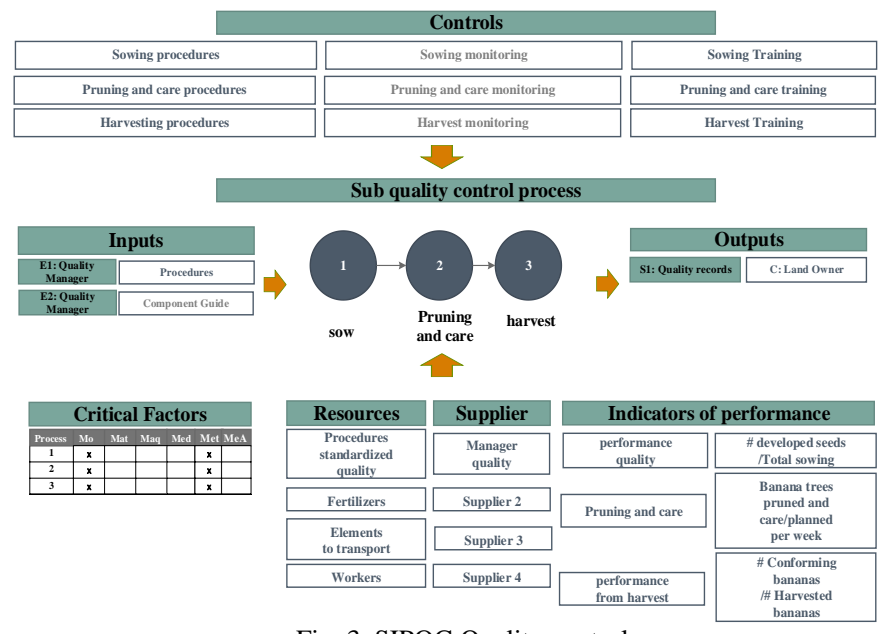

Fig. 3. SIPOC Quality control.

As stated in the SIPOC diagram shown in Figure 3, the inputs to the process are the procedures defined in quality planning and the component guide. The process has been classified into three stages: sowing, pruning and care, and finally the harvest. The resources for this subprocess are standardized quality procedures, fertilizers, loading elements and personnel. Likewise, critical factors have been identified for each activity. For example, for planting, the labor and method are critical factors. The controls proposed are procedures, farmer monitoring and training for each of the stages of the quality control process.

For this subprocess, indicators such as quality yield, pruning, and crop care and yield have been designated:

1) Percentage of yield in the sowing: Percentage of yield in the sowing: The sowing is a critical process because it determines how productive a farmer will be after a period in which it can be identified which seeds will bear fruit or not, approximately said period is 4 months, so It means a significant loss of time, land and investment. This indicator seeks to ensure that the percentage of fructified seeds is greater than $90 \%$ so that a large increase in banana production is generated. This translates into increased sales for banana trees, as they offer bananas at a higher price.

2) Percentage of yield of cared and pruned banana plantation according to the schedule per week: The pruning and care process is considered relevant, since it influences the final appearance that the banana will have when it is harvested, as well as enhancing other characteristics of the fruit. The objective of this indicator is to ensure that the percentage exceeds $95 \%$ of the total, so that the effects of productivity in the banana plantations increase and mainly improve the appearance of the product at the time of harvest.

3) Percentage of crop yield in crops: The harvest process, because it is the final part in this, it must be ensured that the greater amount of the harvested is considered a compliant product, since the sale generated decreases according to the quantity of bananas not Conformed identified. The objective of this indicator is to achieve that the yield exceeds $90 \%$ of the total products harvested, so that higher compliant products are achieved and therefore a higher income, because wholesalers usually give a lower price for bananas with some defect.

\section{Support level: Internal quality audits and training}

On the one hand, the quality audit subprocess will establish the audit plan that will be used to verify that the standards and procedures comply with what is planned at the strategic level. In addition, non-conforming processes will be identified through the results obtained after the audit has been carried out in order to propose solutions that correct the nonconformity. Then, the solutions are implemented so that the following audit can show that the nonconformities have been resolved. It should be considered that for each audit carried out, feedback should be given to the participants in the production chain, mainly to the owner of the farm.

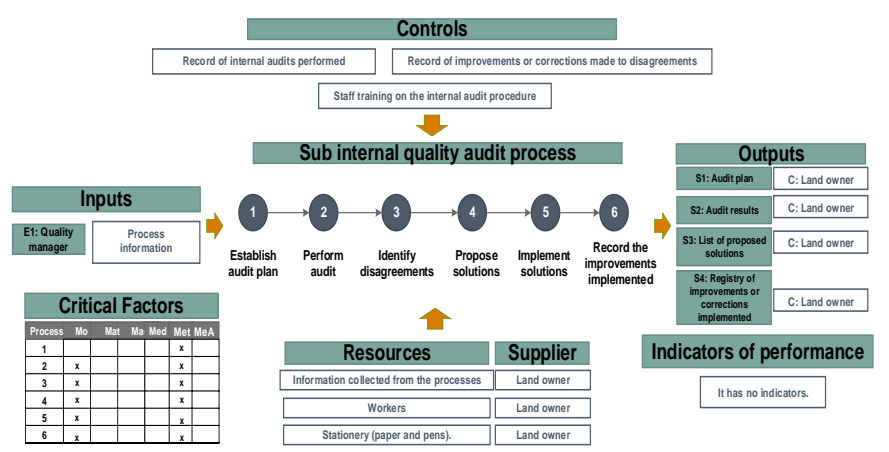

Fig. 4. SIPOC Quality audit.

As stated in the SIPOC diagram shown in Figure 4, the input for the subprocess is the process information. The outputs of the subprocess are the audit plan, the results of the 
audit, the list of the proposed solutions and the record of the improvements or corrections implemented. The process has been established in six stages: establish the audit plan, perform the audit, identify disagreements, propose solutions, implement solutions and record the improvements implemented. In addition, critical factors have been identified for each; In the case of the first stage, labor and method are its critical factors. In relation to this, controls such as training personnel on the procedure and recording audits have been established; in addition to the registry of improvements applied. The resources used are the information collected from the processes carried out by the personnel in the farm. On the other hand, the training subprocess will identify the training needs and assess the training carried out based on the proposed quality management process

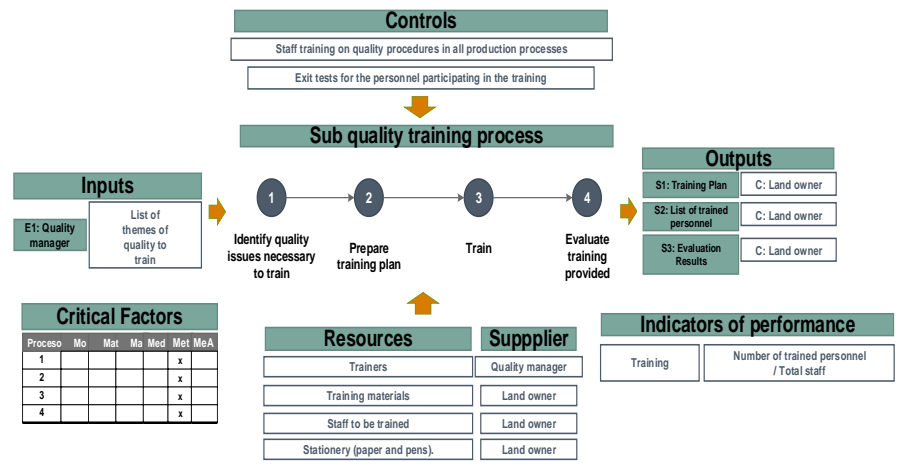

Fig. 5. SIPOC Quality training.

As stated in the SIPOC diagram shown in Figure 5, the entry for the subprocess is the list of quality issues to be trained. The outputs of the subprocess are the training plan, the list of trained personnel and the results of the evaluations carried out. The process has been established in four stages: identify quality issues necessary to train, develop the training plan, conduct training and evaluate the training. In addition, critical factors have been identified for each; In the case of the first stage, the method is its critical factor. In this regard, controls such as staff training regarding quality procedures in all production processes and exit tests for participating staff have been established. The resources used by trainers, training materials, personnel to be trained and useful as papers and pens.

The following indicator is presented for the quality training subprocess:

1) Percentage of trained workers: An increase in the percentage of workers trained in issues related to quality management also indicates an increase in productivity, since the proposed international standards can be more easily implemented. The workers will have knowledge of the controls and the quality measurements in each process, which will result in a decrease in the amount of loss of bananas or seeds (little son).

\section{RESULTS}

For the validation of the proposed Quality Management model, the implementation of a pilot plan in the farmer's farm began and three matrices were generated, which will allow users to provide a concise evaluation of the pilot plan in accordance with the aspects considered as important for the research group, write down results of the implementation and analyze the impacts that may arise when implementing the proposal. These matrices are the user validation matrix, the results matrix and the impact matrix.

\section{A. Pilot plan}

The implementation of the pilot plan began on October 10, 2019 at a farmer's farm, located in the area called "Los Platanales de Mala", and lasts approximately one year, since that time is the one that has elapsed since the sowing from grandparents to the harvest of bananas. However, the data collection will be from March 2020, since from that month it can be determined which children are going to bear fruit correctly later and which are not, which is relevant information for the planting yield indicator raised in the quality control thread. Then, over the course of the months, information may continue to be collected to measure the other indicators raised until reaching the harvest month. For the implementation of the proposed process, three stages were proposed, as can be seen in Figure 6.
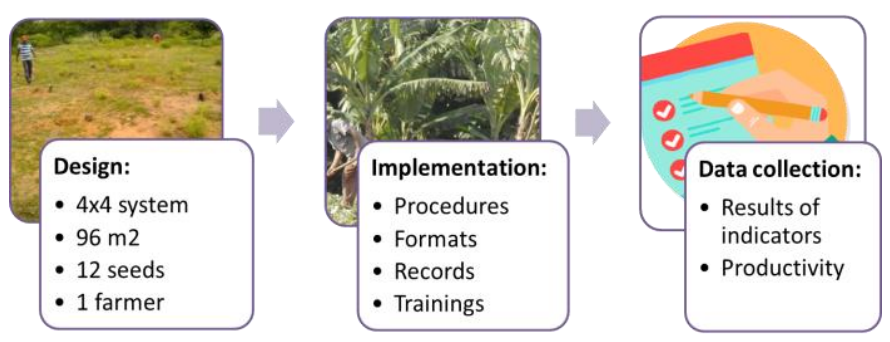

Fig. 6. Stages of the pilot plan.

For the design stage of the pilot plan, a $4 \times 4$ sowing system was considered, that is, the space between each sow or seed sown had to be 4 meters. In addition, a space of $96 \mathrm{~m} 2$ was used, where 12 seeds could be sown with the help of the farmer, who owns the farm, and an additional farmer.

For the stage of implementation of the pilot plan, all the procedures, formats and records proposed in this research were used, as well as training related to the quality management process proposed to the participants.

Finally, the data collection stage will be carried out from March 2020 with the help of the five indicators proposed in the quality management process, which will confirm if an increase in productivity was achieved.

\section{B. Results matrix}

After carrying out the pilot plan of the proposed model of the Quality Management process at the farm of a farmer 
located in the city of Mala, the results obtained will be collected according to the indicators proposed for each subprocess and will be recorded in the matrix detailed in Table
1 in order to validate that the model can increase the productivity of banana farmers in the city of Mala.

TABLE I

RESULTS MATRIX

\begin{tabular}{|l|l|l|l|}
\hline Indicator & Description & Current Value & $\begin{array}{l}\text { Expected Value After } \\
\text { Implementation }\end{array}$ \\
\hline $\begin{array}{l}\text { Percentage of standards met } \\
\text { according to those proposed. }\end{array}$ & $\begin{array}{l}\text { nsure that the standards met exceed 98\% of the total proposed standards, so } \\
\text { that higher quality products are achieved with a significant increase in } \\
\text { productivity. }\end{array}$ & $0 \%$ compliance & $100 \%$ \\
\hline $\begin{array}{l}\text { Percentage of quality yield in } \\
\text { planting. }\end{array}$ & $\begin{array}{l}\text { Ensure that the percentage of fructified seeds is greater than 90\% so that a } \\
\text { large increase in banana production is generated. }\end{array}$ & $80 \%$ & $92 \%$ \\
\hline $\begin{array}{l}\text { Percentage of pruned banana trees } \\
\text { and care in percentage according to } \\
\text { the schedule established per week. }\end{array}$ & $\begin{array}{l}\text { Ensure that the percentage exceeds 95\% of the total, so that the effects of } \\
\text { productivity in the banana plantations increase and mainly improve the } \\
\text { appearance of the product at the time of harvest. }\end{array}$ & $85 \%$ & $95 \%$ \\
\hline $\begin{array}{l}\text { Percentage of crop yield of banana } \\
\text { crops. }\end{array}$ & $\begin{array}{l}\text { Achieve that the yield exceeds 90\% of the total products harvested, so that } \\
\text { greater compliant products are achieved and therefore a higher income, } \\
\text { because wholesalers usually give a lower price for bananas with some } \\
\text { defect. }\end{array}$ & $87 \%$ & $93 \%$ \\
\hline $\begin{array}{l}\text { Percentage of personnel trained in } \\
\text { issues related to Quality } \\
\text { Management. }\end{array}$ & $\begin{array}{l}\text { Determine the number of farmers who are trained in issues related to Quality } \\
\text { Management and ensure that they exceed 95\% of total farmers. }\end{array}$ & $0 \%$ compliance & $100 \%$ \\
\hline
\end{tabular}

According to table 1, after the implementation of the pilot plan it is expected to achieve $100 \%$ of the quality standards met according to those proposed, $92 \%$ in planting performance, $95 \%$ in the percentage of banana plantations in accordance with the established programming, $93 \%$ in the yield of the harvest and that $100 \%$ of the personnel that participates in the work of plantain cultivation is trained in issues related to quality management. These improvement percentages are based on the interview with the farmer, who is the owner of the farm where the implementation is being carried out and, in addition, is one of the leaders of the Association of Banana and Vine Producers of Mala (Aprovima). Finally, the actual results will be obtained from March 2020.

\section{DISCUSSION}

For the analysis of the expected results, an economic evaluation is proposed according to the improvement proposal worked on in this research project. Therefore, the improvement in the sowing process will be mentioned first, then the improvement in the volume of production and, finally, the impact on the farmer's economic income. The sowing process is considered the main point, because in this process the most important problem in the banana production process is presented. The considerations we have for the economic evaluation, according to the information provided by the farmers and the information reviewed in the sources of consultation, are the following.

The research carried out integrates basic and low-cost tools, as well as the use of expensive technology. Therefore, it is expected to reduce post-harvest waste to $8 \%$, a recent study in Peru indicated that the decrease in the organic apple sector is $12 \%$. This affects the economy of the producers. The number of exportable products in the organic sector is also expected to increase.

1) Farmers, according to the need for the campaign, hire staff for planting and other cultivation work, which are requested to sow in a $4 \times 4$ system. However, in the process it is estimated that of every 25 seeds sown by this staff only they get to fructify an approximate of 20 seeds

2) approximate date after which the farmer can notice that the seed was fruitful or not is 3 months after sowing.

3) The entire campaign is lost for the coming year in the case its raised.

4) According to the proposed process, having a standardized sowing process will generate the greatest amount

Table II summarizes the data used for the economic evaluation.

\begin{tabular}{|c|c|c|}
\hline \multicolumn{2}{|c|}{$\begin{array}{l}\text { TABLE II } \\
\text { DATA }\end{array}$} & \\
\hline Description & $\begin{array}{l}\text { Before the } \\
\text { project } \\
\text { (Current) }\end{array}$ & $\begin{array}{l}\text { After the } \\
\text { project } \\
\text { (Future) }\end{array}$ \\
\hline Expected seeds & 25 & 25 \\
\hline Real seeds & 20 & 23 \\
\hline Inefficiency & $20 \%$ & $8 \%$ \\
\hline Workers & 5 & 5 \\
\hline Sowing & 1000 & 1000 \\
\hline Total seeds sown per worker & 200 & 200 \\
\hline Groups of 25 seeds per worker & 8 & 8 \\
\hline Total seeds lost per worker & 40 & 16 \\
\hline Total seeds that really bear fruit & 800 & 920 \\
\hline $\begin{array}{l}\text { ANNUAL PRODUCTION (in } \\
\text { banana heads) }\end{array}$ & 977 & 1123 \\
\hline
\end{tabular}

Finally, for both cases a similar sale price is estimated $(\$$ 10.51 / Head) as shown in Table III. 


TABLE III
DATA
\begin{tabular}{|l|l|}
\hline Average Annual Income \\
\hline Current system & 10,270 USD/year \\
\hline Proposed system & 11,811 USD/year \\
\hline
\end{tabular}

From the tables shown, it can be interpreted that, at the same sale price and under a proposed system, the expected average annual income is much higher than under the current production system applied by banana farmers, since they grow by $15 \%$.

After having analyzed the economic increase when implementing the proposed quality model, a group of future lines of research arise, which allow to deepen the quality management for the farmers and generate knowledge regarding the improvement of the proposed model. As a first line of research, the study of how small farmers can achieve their entry to external markets is recommended, since although it is true that quality management will allow them to offer a product according to the standards demanded, it also has to Study the entry successes part.

On the other hand, a second line of research would be the in-depth study of the certifications that contribute to the competitiveness of the Mala banana in the interior and exterior of the country. This line of research would benefit farmers' profitability and the quality management process itself, since the structure would be completer and more fit those realities. A third line of research could be the study or implementation of the environmental management process, as it is a requirement that many accreditors ask for.

As a fourth line of research, a study of the Human Resources process is proposed, since this process is not included in the general proposal because each process has among its subprocesses the training. However, it would add value to the improvement of the processes of having Human Resources, since it would be in charge of organizing and carrying out all the necessary training to transmit knowledge to the managers of the farmers.

Finally, as a fifth line, the study of the Commercial Management process is proposed, because the basic management model requires a process that has direct contact with customers or wholesalers who wish to acquire the bananas produced. It is important to emphasize that this process will be very useful once the proposal is executed, that is, when a high-performance banana is obtained to offer it to the most demanding clients in the market.

\section{CONCLUSIONS}

A Quality Management process was proposed to meet customer requirements based on the various guidelines proposed in each process in accordance with international standards, which are expected to have positive results after their application in the city of Mala.
A large number of banana farmers decrease their prices due to claims from the wholesaler on the following aspects in the final product: physical damage to the banana, they have a very small size, among others. It is concluded that, with the proposed processes and based on the characterization of processes, the number of claims for these factors will be reduced by $6 \%$, since it is expected to obtain $93 \%$ yield in the harvest after the implementation of the plan pilot.

Currently, daily production is measured in two different ways: a count of cultivated seeds is made, which is done by $60 \%$ of the banana farmers surveyed, or the cultivated space ( $\mathrm{m} 2$ or Ha) is measured, which is done by a $32 \%$ of these farmers, and the other $8 \%$ simply do not measure the right amount of sown seeds. However, these two ways of measuring daily production do not provide the exact amounts and, therefore, are not reliable sources for measurement. Therefore, the proposed subprocesses will help control this through the use of formal records where production related data will be recorded daily and each subprocess will provide the steps to follow for proper filling.

A quality training subprocess is proposed that seeks to ensure that all banana farmers train their workers on issues related to international labor standards, which would result in a $100 \%$ increase in personnel trained on quality issues, since currently No fund meets that knowledge. In order to have a process control based on continuous improvement, the proposed subprocesses will help to efficiently manage the processes involved in banana production. This will achieve a $20 \%$ reduction in the lack of communication between the various banana farmers in Mala, as it seeks to integrate and standardize their agricultural activities according to the proposed quality model.

In addition, 7\% of banana banana farmers in Mala currently have some certification. This percentage is very small, due to the lack of standardization in the banana production processes that is required to obtain certifications. Therefore, after the implementation of the proposed quality model is expected to increase by $10 \%$ the number of banana farmers who have some certification, which would help to improve the quality of the product sold, as well as the price and, subsequently, the farmer's income.

Regarding the proposed quality process and taking into account that the objective of banana farmers is to increase productivity, it is concluded that this process will provide the international guidelines used by Ecuador to increase production. Likewise, it will assign the guidelines to be followed so that inspections and quality controls are carried out at each productive stage.

In addition, the processes will be audited to verify if the guidelines established by each quality control are being met. Finally, farmers will be trained on quality issues so that they know and apply quality standards. 


\section{VII.RECOMMENDATIONS}

Peru should take as an example the case of success of Ecuador where said government implemented the agency called Agrocalidad, which is dedicated to the regularization of processes in the agricultural sector, as well as, supervise that the guidelines established by said agency are met in order to achieve a national standardization. This affected the increase in production in Ecuador, as well as the increase in product quality and export.

The Peruvian government must support banana plantain farmers to obtain certain financing that allows them to access the certifications and thereby achieve to increase the quality of their product and its market value, which will increase the productivity of those mentioned.

Although the proposed model is a tool that is considered taking into account the considerations for a successful implementation, there could be variants that are not controlled by the same process such as climate change or possible natural phenomena. Given this, it is recommended to document these necessary changes, so that later models take into account the other variables. For that reason, in the case that the proposal is to be applied in another banana area of the country, it is recommended to carry out a pre-site evaluation to be able to make the necessary adjustments, in accordance with the reality of the area. In this way, the implementation will be more effective and the expected benefits will be obtained.

\section{REFERENCES}

[1] Mazzola. Gestión de la Innovación en micro, pequeñas y medianas empresas: un estudio en un clúster electrónico brasileño. Independent Journal of Management \& Production, Brazil. 2018

[2] F. H. Lang, "Standardization for information technology (IT) - status: November 1986," Comput. Stand. Interfaces, vol. 5, no. 3, pp. 125-136, 1986.

[3] J. Liu, S. Rahman, S. Sriboonchitta, and A. Wiboonpongse, "Enhancing productivity and resource conservation by eliminating inefficiency of thai rice farmers: A zero inefficiency stochastic frontier approach," Sustain., vol. 9, no. 5, 2017.

[4] H. R. Páez and L. G. Quintas, "Estrategia de exportación desde Argentina hacia México de cuadernos de espiral," Trimest. Econ., vol. 75, no. SPEC. ISS., pp. 235-260, Jan. 2008.

[5] K. R. Sridhar and C. N. Ambarish, "Pill millipede compost: A viable alternative to utilize urban organic solid waste," Curr. Sci., vol. 104, no. 11, pp. 1543-1547, Jun. 2013.

[6] Rojas, J; Vegas, U; Domínguez, R. 2010. Núcleo para la producción rápida de semilla de banano orgánico en campo en el Perú. pp 587- 593. En: Memorias de la XIX Reunión Internacional ACORBAT 2010. Medellín, Colombia.

[7] C.A. O'Sullivan, "Strategies to improve the productivity, product diversity and profitability of urban agriculture ," Inf. Process. Agric., Agricultural Systems 174 (2019) 133-144.

[8] B. Dal, P. Tugwell, and R. Greatbanks, "Overall equipment effectiveness as a measure of operational improvement - A practical analysis," Int. J. Oper. Prod. Manag., vol. 20, no. 12, pp. 1488-1502, 2000.

[9] S. Klein and D. Bähre, "Analysis of the Movements in Relation to the Degrees of Freedom in Precision Honing," in Procedia Manufacturing, 2018, vol. 26, pp. 286-293.

[10]F. Wang, X. Fang, X. Chen, and X. Li, "Impact of inventory inaccuracies on products with inventory-dependent demand," Int. J. Prod. Econ., vol. 177, pp. 118-130, Jul. 2016.
[11]Scherkenback. (1996). La Ruta Deming hacia la Mejora Continua. México: CECSA. 